\title{
Maternal personality profile of children affected by migraine
}

This article was published in the following Dove Press journal:

Neuropsychiatric Disease and Treatment

10 September 2013

Number of times this article has been viewed

\section{Maria Esposito' \\ Michele Roccella ${ }^{2}$ \\ Beatrice Gallai ${ }^{3}$ \\ Lucia Parisi ${ }^{2}$ \\ Serena Marianna Lavano ${ }^{4}$ \\ Rosa Marotta ${ }^{4}$ \\ Marco Carotenuto' \\ 'Center for Childhood Headache, Second University of Naples, Naples, Italy; ${ }^{2}$ Department of Psychology, University of Palermo, Palermo, Italy; ${ }^{3}$ Unit of Child and Adolescent Neuropsychiatry, University of Perugia, Perugia, Italy; ${ }^{4}$ Department of Psychiatry, Magna Graecia University of Catanzaro, Catanzaro, Italy}

Correspondence: Lucia Parisi

Child Neuropsychiatry, Department of Psychology, University of

Palermo, I5 Viale delle Scienze,

Palermo 90128, Italy

Tel +3909123897756

Fax +39 09| 65I 3825

Email lucia.parisi@unipa.it
Background: Empirical evidence of the important role of the family in primary pediatric headache has grown significantly in the last few years, although the interconnections between the dysfunctional process and the family interaction are still unclear. Even though the role of parenting in childhood migraine is well known, no studies about the personality of parents of migraine children have been conducted. The aim of the present study was to assess, using an objective measure, the personality profile of mothers of children affected by migraine without aura (MoA).

Materials and methods: A total of 269 mothers of MoA children (153 male, 116 female, aged between 6 and 12 years; mean $8.93 \pm 3.57$ years) were compared with the findings obtained from a sample of mothers of 587 healthy children ( 316 male, 271 female, mean age $8.74 \pm 3.57$ years) randomly selected from schools in the Campania, Umbria, Calabria, and Sicily regions. Each mother filled out the Minnesota Multiphasic Personality Inventory - second edition (MMPI-2), widely used to diagnose personality and psychological disorders. The $t$-test was used to compare age and MMPI-2 clinical basic and content scales between mothers of MoA and typical developing children, and Pearson's correlation test was used to evaluate the relation between MMPI-2 scores of mothers of MoA children and frequency, intensity, and duration of migraine attacks of their children.

Results: Mothers of MoA children showed significantly higher scores in the paranoia and social introversion clinical basic subscales, and in the anxiety, obsessiveness, depression, health concerns, bizarre mentation, cynicism, type A, low self-esteem, work interference, and negative treatment indicator clinical content subscales $(P<0.001$ for all variables). Moreover, Pearson's correlation analysis showed a significant relationship between MoA frequency of children and anxiety $(r=0.4903, P=0.024)$ and low self-esteem $(r=0.5130, P=0.017)$, while the MoA duration of children was related with hypochondriasis $(r=0.6155, P=0.003)$, hysteria $(r=0.6235, P=0.003)$, paranoia $(r=0.5102, P=0.018)$, psychasthenia $(r=0.4806$, $P=0.027)$, schizophrenia $(r=0.4350, P=0.049)$, anxiety $(r=0.4332, P=0.050)$, and health concerns $(r=0.7039, P<0.001)$ MMPI- 2 scores of their mothers.

Conclusion: This could be considered a preliminary study that indicates the potential value of maternal personality assessment for better comprehension and clinical management of children affected by migraine, though further studies on the other primary headaches are necessary.

Keywords: MMPI-2, childhood migraine, maternal personality

\section{Introduction}

Migraine without aura (MoA) may be considered the most frequent primary headache in childhood. ${ }^{1}$ Children affected by migraine have been consistently shown to have more recurrent illnesses ${ }^{2}$ and school absences, decreased academic performance, social stigma, and impaired ability to establish and maintain peer relationships. ${ }^{3,4}$ In 
fact, the quality of life in children with migraine has been shown to be impaired to a degree similar to that in children with arthritis or cancer. ${ }^{5}$

In order to improve the quality of life of children affected by MoA, alternative drugs and methods have been applied to limit adverse effects, ${ }^{6-9}$ and many nondrug treatments have been useful in MoA children. ${ }^{10-13}$

Most studies concerning the impact of migraine have focused on its effects on many aspects of life. ${ }^{14-21}$ In 1998, Mannix and Solomon reported that people affected by migraine and chronic headaches have a significantly reduced quality of life, even between attacks, ${ }^{22}$ raising the question of the effects of migraine on quality of life in the broader context of the family. A study on families found that $60 \%$ of the participants with migraine believed that their families were significantly affected by their migraines. ${ }^{23}$ Indeed, it has been argued that the impact of any illness is not only experienced by the individual but also by those around them who are exposed to the various forms of psychological, economic, and social stressors that accompany an illness, ${ }^{24}$ such as the comparatively high levels of parental stress among the parents of children affected by MoA. ${ }^{25}$

On the other hand, the empirical evidence of the important role of the family in primary pediatric headache has grown significantly in the last few years, although the interconnections between the dysfunctional process and the family interaction are still unclear. ${ }^{26}$ However, some authors suggest that migraine could be considered a sort of familial disorder. ${ }^{27}$ Even though the role of parenting in childhood migraine is well known, no studies about the personality of parents of migraine children have been conducted.

Therefore, the aim of present study was to assess, using an objective measure, the personality profile of mothers of children affected by MoA.

\section{Materials and methods}

\section{Study population}

A total of 452 children consecutively referred for MoA were enrolled at the Center for Childhood Headache of the Clinic of Child and Adolescent Neuropsychiatry at the Second University of Naples, to the Unit of Child and Adolescent Neuropsychiatry at Perugia University, to the Azienda Sanitaria Locale of Terni, to the Department of Psychiatry at the University of Catanzaro, and to Child Neuropsychiatry at the University of Palermo.

The diagnosis of MoA was made according to the pediatric criteria of the 2013 International Headache Society classification criteria. ${ }^{28}$ Exclusion criteria were allergies, endocrinological problems (ie, diabetes), preterm birth, ${ }^{29,30}$ neurological (ie, epilepsy, all types of headache other than MoA) or psychiatric symptoms (attention deficit/hyperactivity disorder, depression, behavioral problems), mental retardation (IQ $\leq 70$ ), borderline intellectual functioning (IQ ranging from 71 to 84 ), ${ }^{31,32}$ overweight (body mass index [BMI] $\geq 85$ th percentile) or obesity (BMI $\geq 95$ th percentile), ${ }^{33,34}$ sleep disorders, ${ }^{14,35-39}$ primary nocturnal enuresis, ${ }^{40-42}$ and anticonvulsant ${ }^{43,44}$ or psychoactive drug administration.

No children in prophylactic treatment for migraine were recruited for this study. Mothers affected by psychiatric (ie, depression, anxiety, panic attacks, psychosis) or neurological illness or affected by headaches were excluded. Finally, 269 (59.52\% from starting population) mothers of MoA children (153 male, 116 female; aged between 6 and 12 years; mean $8.93 \pm 3.57$ years) were considered eligible for the present study.

Following recruitment, there was a 4-month run-in period to verify headache characteristics. At the end of run-in, monthly headache frequency and mean headache duration were assessed from daily headache diaries kept by all the children. Headache intensity was assessed on a $0-10$ visual analog scale (VAS), with 0 being "no pain" and 10 being "the worst possible pain," as previously reported. ${ }^{10,12,13}$ The minimum length of headache required for admission in this study was 7 months, with a minimum of four attacks monthly, each lasting for a duration of 1 hour, according to International Classification of Headache Disorders III criteria. ${ }^{28}$

The results were compared with the findings obtained in a sample of 587 healthy controls (316 male, 271 female; mean age $8.74 \pm 3.57$ years) randomly selected from schools in the Campania, Umbria, Calabria, and Sicily regions. The subjects in both groups were recruited from the same urban area; participants were all Caucasian, and held a middle-class socioeconomic status (between class 2 or class 3, corresponding to $€ 28,000-€ 55,000 /$ year to $€ 55,000-€ 75,000 /$ year, respectively, according to the current Italian economic legislation parameters), as previously reported..$^{17,45}$

All parents gave their written informed consent. The departmental ethics committee at the Second University of Naples approved the study design. The study was conducted according to the criteria of the Declaration of Helsinki. ${ }^{46}$

\section{Measures and procedures}

\section{Minnesota Multiphasic Personality Inventory -} second edition

For assessment of personality habits, each mother filled out the Minnesota Multiphasic Personality Inventory - second 
edition (MMPI-2), ${ }^{47}$ widely used to diagnose personality and psychological disorders. The MMPI- 2 consists of 567 items, all true-or-false format, and usually takes between 1 and 2 hours to be completed. In order to verify the mean differences between the two groups of mothers, we took into account only the two main scales: the clinical basic scale and content scale.

The clinical basic scale is used to evidence different psychotic conditions, and is composed of ten items: hypochondriasis (Hs; to assess a neurotic concern over bodily functioning), depression ( $\mathrm{D}$; originally designed to identify depression, characterized by poor morale, lack of hope in the future, and a general dissatisfaction with one's own life situation), hysteria (Hy; designed to identify the "hysteric" response in stressful situations), psychopathic deviate ( $\mathrm{Pd}$; originally developed to identify psychopathic patients, this scale measures social deviation, lack of acceptance of authority, and amorality, and can be considered also as a measure of disobedience), masculinity/femininity (Mf-f; this scale was designed by the original authors to identify homosexual tendencies, but was found to be largely ineffective; high scores on this scale are related to factors such as intelligence, socioeconomic status, and education; women tend to score low on this scale), paranoia ( $\mathrm{Pa}$; originally developed to identify patients with paranoid symptoms, such as suspiciousness, feelings of persecution, grandiose self-concepts, excessive sensitivity, and rigid attitudes), psychasthenia (Pt; this scale could be considered more reflective of obsessive-compulsive disorder), schizophrenia (Sc; this scale was originally developed to identify schizophrenic patients and reflects a wide variety of areas, including bizarre thought processes and peculiar perceptions, social alienation, poor familial relationships, difficulties in concentration and impulse control, lack of deep interests, disturbing questions of self-worth and self-identity, and sexual difficulties), hypomania (Ma; this scale was developed to identify such characteristics of hypomania as elevated mood, accelerated speech and motor activity, irritability, flight of ideas, and brief periods of depression), social introversion ( $\mathrm{Si}$; this scale is designed to assess the tendency to withdraw from social contacts and responsibilities).

The content scale is composed of 15 items: anxiety (ANX), fears (FRS), obsessiveness (OBS), depression (DEP), health concerns (HEA), bizarre mentation (BIZ), anger (ANG), cynicism (CYN), antisocial practices (ASP), type A (TPA), low self-esteem (LSE), social discomfort (SOD), family problems (FAM), work interference (WRK), and negative treatment indicators (TRT).

In our study, MMPI-2 profiles met all of the following validity criteria: fewer than 30 item omissions, $L$-scale $\leq 65$,
$F$-scale $\leq 100, K$-scale $\leq 65, F(b)$-scale $\leq 100$, variable response inconsistency $T$-score $\leq 80$, true response inconsistency $T$-score $\leq 80$, and raw $F$ - $K$-score $\leq 11$. The MMPI-2 was evaluated by a trained physician (ME) to assess the personality habits of both mothers of MoA and typical developing children.

\section{Statistical analysis}

The $t$-test was used to compare age and MMPI-2 clinical basic and content scales between mothers of MoA children and typical developing children. Pearson's correlation test was used to evaluate the relation between MMPI-2 scores of mothers of MoA children and frequency, intensity, and duration of migraine attacks of their children. $P<0.05$ was considered statistically significant.

\section{Results}

The two study groups were not significantly different for age $(8.93 \pm 3.57$ years in MoA group vs $8.74 \pm 3.57$ in control group, $P=0.519$ ) or sex (ratio male:female 153:116 in MoA group vs 316:271 in control group, $P=0.449$ ).

Among the MoA clinical characteristics, in the MoA group the attacks occurred with a mean frequency of $10.21 \pm 2.69$ a month, a mean duration of $5.92 \pm 4.09$ hours, and a mean intensity of $6.95 \pm 3.41$, according to VAS parameters. In the MMPI-2 clinical basic scale, the mothers of MoA children showed significantly higher scores in the $\mathrm{Pa}$ and $\mathrm{Si}(P<0.001)$ subscales than mothers of typical developing children (Table 1 and Figure 1).

Table 1 and Figure 2 summarize the differences between the MMPI-2 results in mothers of MoA children in respect of mothers' comparisons for the content scale. Pearson's correlation analysis showed a significantly positive relationship between MoA clinical characteristics of studied children and MMPI-2 scores of their mothers. In particular, the MoA frequency of children was significantly positively related with ANX ( $r=0.4903, P=0.024)$ and LSE $(r=0.5130$; $P=0.017)$ MMPI-2 scores of their mothers.

On the other hand, the MoA duration of children was significantly positively related with $\mathrm{Hs}(r=0.6155, P=0.003)$, Hy $(r=0.6235, P=0.003), \mathrm{Pa}(r=0.5102, P=0.018), \mathrm{Pt}$ $(r=0.4806, P=0.027), \mathrm{Sc}(r=0.4350, P=0.049), \mathrm{ANX}$ $(r=0.4332, P=0.050)$, and HEA $(r=0.7039, P<0.001)$ MMPI-2 scores of their mothers.

\section{Discussion}

The main findings of the present study suggested that the personality of mothers of children affected by MoA tends 
Table I Differences in clinical basic scale and in content scale of MMPI-2 test among mothers of MoA and typical developing children (controls)

\begin{tabular}{|c|c|c|c|}
\hline & $\begin{array}{l}\text { MoA } \\
(n=269)\end{array}$ & $\begin{array}{l}\text { Controls } \\
(n=587)\end{array}$ & $P$ \\
\hline Hs & $56.905 \pm|3.17|$ & $54.979 \pm 15.556$ & 0.075 \\
\hline$D$ & $54.143 \pm 9.743$ & $53.292 \pm 10.999$ & 0.276 \\
\hline $\mathrm{Hy}$ & $49.762 \pm 10.163$ & $48.500 \pm 9.147$ & 0.067 \\
\hline Pd & $52.476 \pm 8.813$ & $53.396 \pm 9.346$ & 0.170 \\
\hline Mf-f & $53.809 \pm 7.639$ & $52.354 \pm 12.828$ & 0.081 \\
\hline $\mathrm{Pa}$ & $56.809 \pm|1.93|$ & $50.917 \pm 9.380$ & $<0.001$ \\
\hline $\mathrm{Pt}$ & $52.667 \pm 13.904$ & $51.479 \pm 12.331$ & 0.207 \\
\hline Sc & $55.524 \pm 10.299$ & $54.125 \pm 11.139$ & 0.077 \\
\hline $\mathrm{Ma}$ & $54.619 \pm 14.589$ & $52.937 \pm 13.759$ & 0.099 \\
\hline $\mathrm{Si}$ & $54.762 \pm 8.927$ & $50.042 \pm 8.490$ & $<0.001$ \\
\hline ANX & $59.814 \pm 9.929$ & $50.958 \pm 8.158$ & $<0.001$ \\
\hline FRS & $58.667 \pm 11.114$ & $56.792 \pm 15.067$ & 0.065 \\
\hline OBS & $57.809 \pm 11.931$ & $50.333 \pm 8.740$ & $<0.001$ \\
\hline DEP & $54.524 \pm 9.948$ & $49.042 \pm 7.217$ & $<0.001$ \\
\hline HEA & $61.571 \pm 11.902$ & $52.375 \pm 7.731$ & $<0.001$ \\
\hline $\mathrm{BIZ}$ & $59.381 \pm 11.49 \mid$ & $52.333 \pm 7.054$ & $<0.001$ \\
\hline ANG & $50.809 \pm 9.943$ & $49.250 \pm 12.078$ & 0.061 \\
\hline CYN & $59.714 \pm 11.136$ & $53.875 \pm 10.878$ & $<0.001$ \\
\hline ASP & $53.095 \pm 8.431$ & $51.729 \pm 10.860$ & 0.065 \\
\hline TPA & $57.57 \mathrm{I} \pm 11.952$ & $51.542 \pm 9.563$ & $<0.001$ \\
\hline LSE & $56.38 I \pm 8.640$ & $48.792 \pm 6.461$ & $<0.001$ \\
\hline SOD & $53.381 \pm 11.084$ & $52.583 \pm 12.683$ & 0.379 \\
\hline FAM & $51.095 \pm 8.312$ & $50.896 \pm 8.745$ & 0.749 \\
\hline WRK & $57.190 \pm 9.647$ & $49.854 \pm 5.975$ & $<0.001$ \\
\hline TRT & $57.667 \pm 10.432$ & $52.396 \pm 7.718$ & $<0.001$ \\
\hline
\end{tabular}

Note: $P<0.05$ was considered statistically significant (t-test).

Abbreviations: MMPI-2, Minnesota Multiphasic Personality Inventory - second edition; MoA, migraine without aura; Hs, hypochondriasis; D, depression; Hy, hysteria; Pd, psychopathic deviate; Mf-f, masculinity/femininity; Pa, paranoia; Pt, psychasthenia; Sc, schizophrenia; Ma, hypomania; Si, social introversion; ANX, anxiety; FRS, fears; OBS, obsessiveness; DEP, depression; HEA, health concerns; BIZ, bizarre mentation; ANG, anger; CYN, cynicism; ASP, antisocial practices; TPA, type A; LSE, low self-esteem; SOD, social discomfort; FAM, family problems; WRK, work interference; TRT, negative treatment indicators.

to be different compared to controls, with a significant correlation with some migraine characteristics. We preferred to focus exclusively on MoA, because it is the most frequent type of primary headache in childhood and also because MoA takes a significant toll on the quality of life for people affected and their family members. ${ }^{25,48}$ Consequently, chronic migraine pain may negatively influence daily functioning, emotions, and roles in social and family contexts. ${ }^{48}$ Moreover, we have to take into account that most studies on the personality traits of migraineurs are focused on adult subjects. ${ }^{49-54}$ These studies evidenced that psychiatric disorders, including depression and anxiety, can be concomitant with the presence of migraine, adding significant morbidity. ${ }^{55}$

Overall behavioral disorders have been reported as more common in children who experience headache than in controls. ${ }^{56}$ Specifically, internalizing symptoms are common in children with headaches, while externalizing symptoms (eg, rule-breaking and aggressivity) are not significantly more common than in controls..$^{57,58}$

On the other hand, in 2008 Radat et $\mathrm{al}^{59}$ showed a higher prevalence of anxiety and depression in children affected by MoA, while other reports showed low levels of self-concept, ${ }^{60}$ higher prevalence of harm-avoidance temperamental style, ${ }^{61}$ and other new and suggestive comorbidities. ${ }^{14-19}$

Alternatively, psychiatric disorders that run in families, specifically anxiety and mood disorders, are particularly frequent in migraineurs and their relatives, ${ }^{62}$ and children affected by migraine seem to be characterized by an higher prevalence of psychiatric disorders in parents than comparisons, ${ }^{63}$ suggesting that a sort of genetic cotransmission of anxiety and depression traits could exist in migraineurs, ${ }^{62}$ and evidence is pointing in this direction. ${ }^{64}$ Even though many reports have shown the co-occurrence of psychiatric symptoms in subjects affected by migraine, ${ }^{25,62,63}$ there have been no specific reports on the personality aspect of mothers not affected by headache who have children with MoA.

Moreover, social learning theory postulates that children's perception of their physical symptoms can be altered via parental modeling, ${ }^{65}$ which may affect the expression of pain and functionally somatic symptoms. Children with recurrent unexplained pain report more models and positive reinforcement for pain behavior than children with recurrent explained pain. ${ }^{66}$ Parental stress and psychopathology may also play a role in organic diseases, such as MoA. ${ }^{25}$

Family factors, such as parenting styles and family functioning, may be linked with disability levels across children's physical health problems. However, this body of literature is limited by lack of clarity in distinguishing between individual parenting factors (eg, parenting style), dyadic variables (eg, parent-child communication), and family-level variables (eg, family functioning) ${ }^{67} \mathrm{Clinical}$ studies of children with recurrent headaches and abdominal pain show that their parents report greater levels of family problems, ${ }^{68,69}$ marital problems,${ }^{70}$ divorce and child physical abuse, ${ }^{71}$ which we could hypothetically also link to the higher levels in mothers of MoA children of some MMPI-2 scores: ANX, OBS, DEP, HEA, BIZ, CYN, TPA, LSE, WRK, and TRT ( $P<0.001$ for all variables). Specifically, regarding the greater levels of TPA and CYN, we could hypothesize that the personal traits of rigidity and ambition in mothers could impact on the coping-strategy 


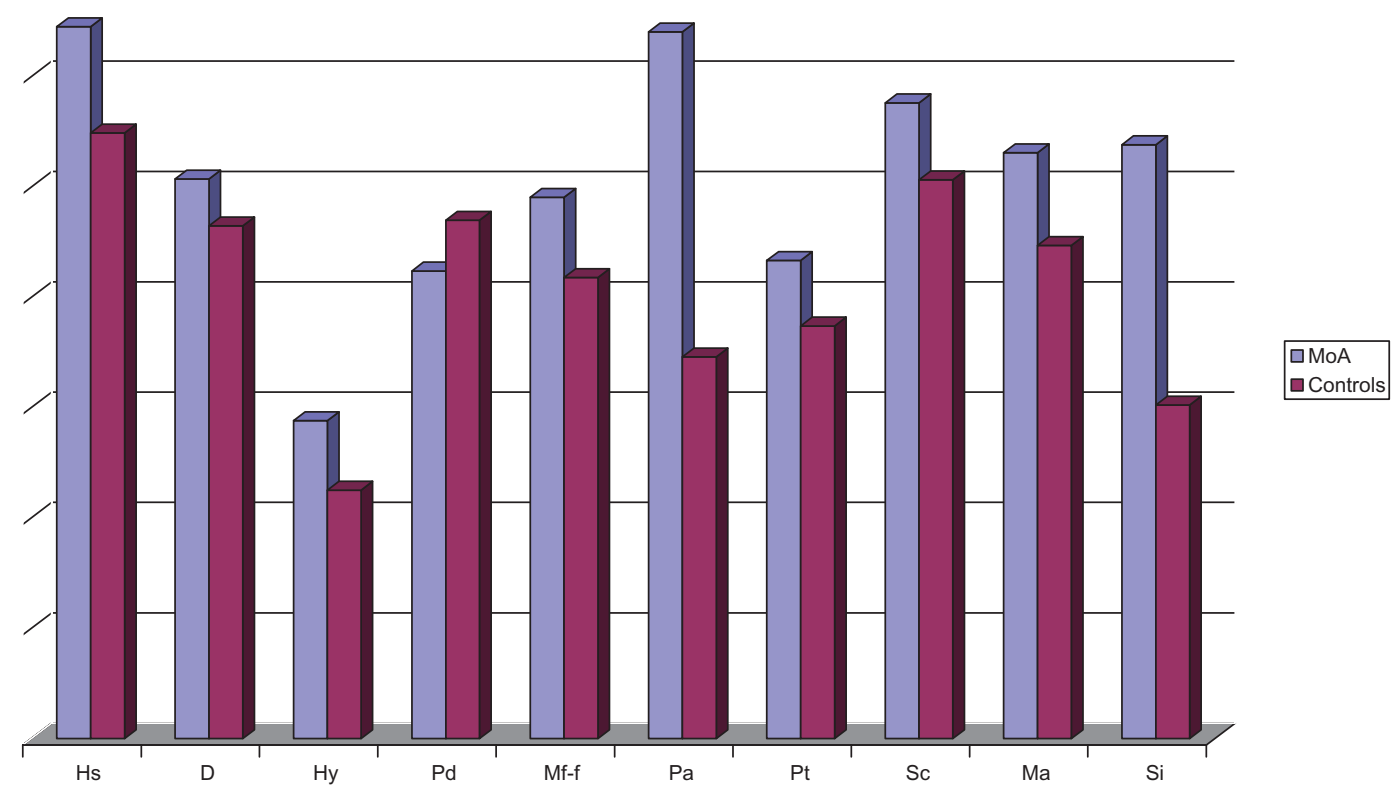

Figure I Comparisons in MMPI-2 clinical basic scales results between mothers of MoA children and mothers of control children.

Abbreviations: MMPI-2, Minnesota Multiphasic Personality Inventory - second edition; MoA, migraine without aura; Hs, hypochondriasis; D, depression; Hy, hysteria; Pd, psychopathic deviate; Mf-f, masculinity/femininity; Pa, paranoia; Pt, psychasthenia; Sc, schizophrenia; Ma, hypomania; Si, social introversion.

development of children affected by migraine, as the maternal cynism (CYN) could act too. Conversely, a potential link between children's internalizing disorders, parental psychopathology and headaches has been established. ${ }^{72}$
Fagan reported that migraine may be associated with dysfunctional parenting patterns, suggesting that in families where the mother has migraine, children may be at risk of inappropriately or prematurely assuming roles for which they are developmentally unready ${ }^{73}$ On the other hand, migraine

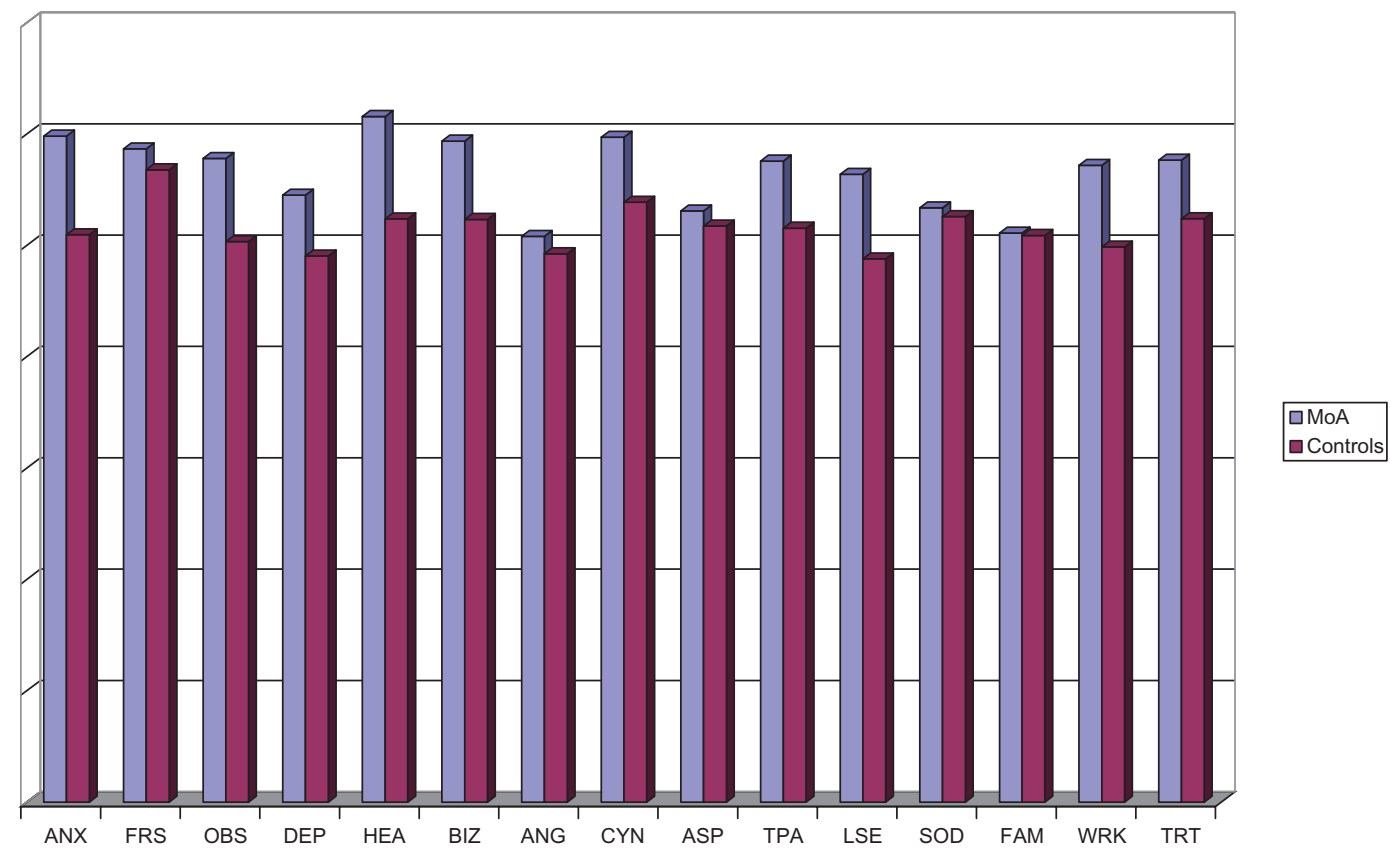

Figure 2 Comparisons in MMPI-2 content scales results between mothers of MoA children and mothers of control children.

Abbreviations: MMPI-2, Minnesota Multiphasic Personality Inventory - second edition; MoA, migraine without aura; ANX, anxiety; FRS, fears; OBS, obsessiveness; DEP, depression; HEA, health concerns; BIZ, bizarre mentation; ANG, anger; CYN, cynicism; ASP, antisocial practices; TPA, type A; LSE, low self-esteem; SOD, social discomfort; FAM, family problems; WRK, work interference; TRT, negative treatment indicators. 
has been also interpreted as a sort of altered communication by children in order to consolidate some intrafamilial trajectories. ${ }^{74,75}$

Alternatively, our findings seem to suggest a potential role of some maternal personality traits (such as $\mathrm{Hs}, \mathrm{Hy}, \mathrm{Pa}, \mathrm{Pt}$, Sc, ANX, and HEA) in children affected by MoA duration perception (Hs, $r=0.6155, P=0.003$; Hy, $r=0.6235$, $P=0.003 ; \mathrm{Pa}, r=0.5102, P=0.018 ; \mathrm{Pt}, r=0.4806, P=0.027$; Sc, $r=0.4350, P=0.049$; ANX, $r=0.4332, P=0.050$; and HEA, $r=0.7039, P<0.001$ ) and MoA frequency (ANX, $r=0.4903, P=0.024$; and LSE, $r=0.5130, P=0.017)$. In fact, we could speculate that some maternal personality traits such as ANX or HEA could alter the health-status perception of children and correct coping strategies, also considering that active coping strategies correspond to intrinsically determined behavior, whereas passive coping corresponds to extrinsically determined behavior with reduced aggression. ${ }^{76}$

Moreover, passive coping strategies have been reported to be associated with high degrees of headache intensity. ${ }^{77}$ Several other coping strategies have been described, but in view of the limited number of studies evaluating them, these strategies were considered less determinant for the study of migraine outcomes. ${ }^{59}$ In this perspective, we could consider our results on the relationship between MMPI-2 basic scales results of mothers, and migraine attacks duration of their children, as the effect of abnormal mothers' coping styles linked to their peculiar personality profiles.

Obviously, we cannot affirm that maternal personality traits play a causative role in MoA disease, because migraine is undoubtedly a neurological disease $\mathrm{e}^{78,79}$ and accompanied by many comorbidities at developmental ages ${ }^{14-19}$ that impact on quality-of-life levels in children affected.

We should take into account a couple of limitations of this study: (1) our data were derived from the administration of a single personality-assessment device and not from a psychiatric clinical evaluation, and (2) we focused only on children affected by MoA, and other types of primary headaches were not considered.

Notwithstanding these limitations, the present study indicates the potential value of maternal personality assessment for better comprehension and clinical management of children affected by migraine, even if further longitudinal studies on the other primary headaches are needed.

In conclusion, our findings could suggest a broader approach to the family of children affected by migraine, with particular attention to the principal caregiver.

\section{Disclosure}

The authors report no conflicts of interest in this work.

\section{References}

1. Merikangas KR. Contributions of epidemiology to our understanding of migraine. Headache. 2013;53:230-246.

2. Powers SW, Patton SR, Hommel KA, Hershey AD. Quality of life in childhood migraines: clinical impact and comparison to other chronic illnesses. Pediatrics. 2003;112:e1-e5.

3. Bigal ME, Lipton RB. The epidemiology, burden, and comorbidities of migraine. Neurol Clin. 2009;27:321-334.

4. Victor T, Hu X, Campbell J, Buse D, Lipton R. Migraine prevalence by age and sex in the United States: a life-span study. Cephalalgia. 2010;30:1065-1072.

5. Gustavsson A, Svensson M, Jacobi F, et al. Cost of disorders of the brain in Europe 2010. Eur Neuropsychopharmacol. 2011;21: 718-779.

6. Wöber-Bingöl C. Pharmacological treatment of acute migraine in adolescents and children. Paediatr Drugs. 2013;15:235-246.

7. El-Chammas K, Keyes J, Thompson N, Vijayakumar J, Becher D, Jackson JL. Pharmacologic treatment of pediatric headaches: a metaanalysis. JAMA Pediatr. 2013;167:250-258.

8. Bonfert M, Straube A, Schroeder AS, Reilich P, Ebinger F, Heinen F. Primary headache in children and adolescents: update on pharmacotherapy of migraine and tension-type headache. Neuropediatrics. 2013;44:3-19.

9. Gallelli L, Avenoso T, Falcone D, et al. Effects of Acetaminophen and Ibuprofen in Children With Migraine Receiving Preventive Treatment With Magnesium. Headache. 2013. In press.

10. Carotenuto M, Esposito M. Nutraceuticals safety and efficacy in migraine without aura in a population of children affected by neurofibromatosis type I. Neurol Sci. 2013. In press.

11. Verrotti A, Agostinelli S, D'Egidio C, et al. Impact of a weight loss program on migraine in obese adolescents. Eur J Neurol. 2013;20(2): 394-397.

12. Esposito M, Ruberto M, Pascotto A, Carotenuto M. Nutraceutical preparations in childhood migraine prophylaxis: effects on headache outcomes including disability and behaviour. Neurol Sci. 2012;33(6): $1365-1368$

13. Esposito M, Carotenuto M. Ginkgolide B complex efficacy for brief prophylaxis of migraine in school-aged children: an open-label study. Neurol Sci. 2011;32(1):79-81.

14. Esposito M, Parisi P, Miano S, Carotenuto M. Migraine and periodic limb movement disorders in sleep in children: a preliminary case-control study. J Headache Pain. 2013;14:57.

15. Esposito M, Roccella M, Parisi L, Gallai B, Carotenuto M. Hypersomnia in children affected by migraine without aura: a questionnaire-based case-control study. Neuropsychiatr Dis Treat. 2013;9:289-294.

16. Esposito M, Pascotto A, Gallai B, et al. Can headache impair intellectual abilities in children? An observational study. Neuropsychiatr Dis Treat. 2012;8:509-513.

17. Esposito M, Verrotti A, Gimigliano F, et al. Motor coordination impairment and migraine in children: a new comorbidity? Eur J Pediatr. 2012;171:1599-1604.

18. Carotenuto M, Esposito M, Precenzano F, Castaldo L, Roccella M. Cosleeping in childhood migraine. Minerva Pediatr. 2011;63: 105-109.

19. Carotenuto M, Esposito M, Pascotto A. Migraine and enuresis in children: an unusual correlation? Med Hypotheses. 2010;75:120-122.

20. Kantor D. The impact of migraine on school performance. Neurology. 2012;79:e168-e169.

21. Ozge A, Saşmaz T, Buğdaycı R, et al. The prevalence of chronic and episodic migraine in children and adolescents. Eur J Neurol. 2013;20: 95-101. 
22. Mannix LK, Solomon GD. Quality of life in migraine. Clin Neurosci. 1998;5:38-42.

23. Smith R. Impact of migraine on the family. Headache. 1998;38: 423-426.

24. Armistead L, Klien K, Forehand R. Parental physical illness and child functioning. Clin Psychol Rev. 1995;15:409-422.

25. Esposito M, Gallai B, Parisi L, et al. Maternal stress and childhood migraine: a new perspective on management. Neuropsychiatr Dis Treat. 2013;9:351-355.

26. Ochs M, Seemann H, Franck G, Verres R, Schweitzer J. Familial body concepts and illness attributions in primary headache in childhood and adolescence. Prax Kinderpsychol Kinderpsychiatr. 2002;51:209-223. German.

27. Siniatchkin M, Gerber WD. Role of family in development of neurophysiological manifestations in children with migraine. Prax Kinderpsychol Kinderpsychiatr. 2002;51:194-208.

28. Headache Classification Committee of the International Headache Society (IHS). The International Classification of Headache Disorders, 3rd edition (beta version). Cephalalgia. 2013;33:629-808.

29. Guzzetta A, Pizzardi A, Belmonti V, et al. Hand movements at 3 months predict later hemiplegia in term infants with neonatal cerebral infarction. Dev Med Child Neurol. 2010;52:767-772.

30. Guzzetta A, D'Acunto MG, Carotenuto M, et al. The effects of preterm infant massage on brain electrical activity. Dev Med Child Neurol. 2011;53 Suppl 4:46-51.

31. Esposito M, Carotenuto M. Intellectual disabilities and power spectra analysis during sleep: a new perspective on borderline intellectual functioning. J Intellect Disabil Res. 2013. In press.

32. Esposito M, Carotenuto M. Borderline intellectual functioning and sleep: the role of cyclic alternating pattern. Neurosci Lett. 2010;19;485: 89-93.

33. Carotenuto M, Santoro N, Grandone A, et al. The insulin gene variable number of tandem repeats (INS VNTR) genotype and sleep disordered breathing in childhood obesity. J Endocrinol Invest. 2009;32: 752-755.

34. Carotenuto M, Bruni O, Santoro N, Del Giudice EM, Perrone L, Pascotto A. Waist circumference predicts the occurrence of sleep-disordered breathing in obese children and adolescents: a questionnaire-based study. Sleep Med. 2006;7:357-361.

35. Carotenuto M, Guidetti V, Ruju F, Galli F, Tagliente FR, Pascotto A. Headache disorders as risk factors for sleep disturbances in school aged children. J Headache Pain. 2005;6:268-270.

36. Carotenuto M, Gallai B, Parisi L, Roccella M, Esposito M. Acupressure therapy for insomnia in adolescents: a polysomnographic study. Neuropsychiatr Dis Treat. 2013;9:157-162.

37. Carotenuto M, Gimigliano F, Fiordelisi G, Ruberto M, Esposito M. Positional abnormalities during sleep in children affected by obstructive sleep apnea syndrome: the putative role of kinetic muscular chains. Med Hypotheses. 2013;81:306-308.

38. Carotenuto M, Esposito M, Parisi L, et al. Depressive symptoms and childhood sleep apnea syndrome. Neuropsychiatr Dis Treat. 2012;8: 369-373.

39. Carotenuto M, Esposito M, Pascotto A. Facial patterns and primary nocturnal enuresis in children. Sleep Breath. 2011;15:221-227.

40. Esposito M, Carotenuto M, Roccella M. Primary nocturnal enuresis and learning disability. Minerva Pediatr. 2011;63:99-104.

41. Esposito M, Gallai B, Parisi L, et al. Primary nocturnal enuresis as a risk factor for sleep disorders: an observational questionnaire-based multicenter study. Neuropsychiatr Dis Treat. 2013;9:437-443.

42. Esposito M, Gallai B, Parisi L, et al. Visuomotor competencies and primary monosymptomatic nocturnal enuresis in prepubertal aged children. Neuropsychiatr Dis Treat. 2013;9:921-926.

43. Coppola G, Auricchio G, Federico R, Carotenuto M, Pascotto A. Lamotrigine versus valproic acid as first-line monotherapy in newly diagnosed typical absence seizures: an open-label, randomized, parallelgroup study. Epilepsia. 2004;45:1049-1053.
44. Coppola G, Licciardi F, Sciscio N, Russo F, Carotenuto M, Pascotto A. Lamotrigine as first-line drug in childhood absence epilepsy: a clinical and neurophysiological study. Brain Dev. 2004;26:26-29.

45. Esposito M, Antinolfi L, Gallai B, et al. Executive dysfunction in children affected by obstructive sleep apnea syndrome: an observational study. Neuropsychiatr Dis Treat. 2013;109:1087-1094.

46. World Medical Association. WMA Declaration of Helsinki: Ethical Principles for Medical Research Involving Human Subjects. FerneyVoltaire, France: WMA; 2008. Available from: http://www.wma.net/ en/30publications/10policies/b3. Accessed April 25, 2013.

47. Butcher JN, Dahlstrom WG, Graham JR, Tellegen A, Kaemmer B. Minnesota Multiphasic Personality Inventory-2 (MMPI-2): Manual for Administration and Scoring. Minneapolis: University of Minnesota Press; 1989.

48. Lipton RB, Bigal ME, Amatniek JC, Stewart WF. Tools for diagnosing migraine and measuring its severity. Headache. 2004;44:387-398.

49. Ishii M, Shimizu S, Sakairi Y, et al. MAOA, MTHFR, and TNF- $\beta$ genes polymorphisms and personality traits in the pathogenesis of migraine. Mol Cell Biochem. 2012;363:357-366.

50. Hedborg K, Anderberg UM, Muhr C. Stress in migraine: personalitydependent vulnerability, life events, and gender are of significance. Ups J Med Sci. 2011;116:187-199.

51. Curone M, Tullo V, Mea E, Proietti-Cecchini A, Peccarisi C, Bussone G. Psychopathological profile of patients with chronic migraine and medication overuse: study and findings in 50 cases. Neurol Sci. 2011; 32 Suppl 1:S177-S179.

52. Luconi R, Bartolini M, Taffi R, et al. Prognostic significance of personality profiles in patients with chronic migraine. Headache. 2007;47: $1118-1124$.

53. Tan HJ, Suganthi C, Dhachayani S, Rizal AM, Raymond AA. The coexistence of anxiety and depressive personality traits in migraine. Singapore Med J. 2007;48:307-310.

54. Abbate-Daga G, Fassino S, Lo Giudice R, et al. Anger, depression and personality dimensions in patients with migraine without aura. Psychother Psychosom. 2007;76:122-128.

55. Breslau N, Schultz LR, Stewart WF, Lipton RB, Lucia VC, Welch KM. Headache and major depression: is the association specific to migraine? Neurology. 2000;54:308-313.

56. Pavone P, Rizzo R, Conti I, et al. Primary headaches in children: clinical findings on the association with other conditions. Int J Immunopathol Pharmacol. 2012;25:1083-1091.

57. Arruda MA, Bigal ME. Behavioral and emotional symptoms and primary headaches in children: a population-based study. Cephalalgia. 2012;32:1093-1100.

58. Margari F, Lucarelli E, Craig F, Petruzzelli MG, Lecce PA, Margari L. Psychopathology in children and adolescents with primary headaches: categorical and dimensional approaches. Cephalalgia. Epub July 4, 2013.

59. Radat F, Mekies C, Géraud G, et al. Anxiety, stress and coping behaviours in primary care migraine patients: results of the SMILE study. Cephalalgia. 2008;28:1115-1125.

60. Esposito M, Gallai B, Parisi L, et al. Self-concept evaluation and migraine without aura in childhood. Neuropsychiatr Dis Treat. 2013;9: 1061-1066.

61. Esposito M, Marotta R, Gallai B, et al. Temperamental characteristics in childhood migraine without aura: a multicenter study. Neuropsychiatric Disease and Treatment. 2013;9:1187-1192.

62. Merikangas KR, Merikangas JR, Angst J. Headache syndromes and psychiatric disorders: association and familial transmission. J Psychiatr Res. 1993;27:197-210.

63. Galli F, Canzano L, Scalisi TG, Guidetti V. Psychiatric disorders and headache familial recurrence: a study on 200 children and their parents. $J$ Headache Pain. 2009;10:187-197.

64. Gonda X, Rihmer Z, Juhasz G, Zsombok T, Bagdy G. High anxiety and migraine are associated with the $\mathrm{s}$ allele of the 5HTTLPR gene polymorphism. Psychiatr Res. 2007;149:261-266. 
65. Bandura A. Self-efficacy: toward a unifying theory of behavioral change. Psychol Rev. 1977;84:191-215.

66. Osborne RB, Hatcher JW, Richtsmeier AJ. The role of social modeling in unexplained pediatric pain. J Pediatr Psychol. 1989;14:43-61.

67. Palermo TM, Chambers CT. Parent and family factors in pediatric chronic pain and disability: an integrative approach. Pain. 2005;119: $1-4$.

68. Anttila P, Sourander A, Metsähonkala L, Aromaa M, Helenius H, Sillanpää M. Psychiatric symptoms in children with primary headache. J Am Acad Child Adolesc Psychiatry. 2004;43:412-419.

69. Emiroglu FN, Kurul S, Akay A, Miral S, Dirik E. Assessment of child neurology outpatients with headache, dizziness and fainting. $J$ Child Neurol. 2004;19:332-336.

70. Zuckerman B, Stevenson J, Bailey V. Stomachaches and headaches in a community sample of preschool children. Pediatrics. 1987;79:677-682.

71. Juang KD, Wang SJ, Fuh JL, Lu SR, Chen YS. Association between adolescent chronic daily headache and childhood adversity: a community-based study. Cephalalgia. 2004;24:54-59.

72. Feldman JM, Ortega AN, Koinis-Mitchell D, Kuo AA, Canino G. Child and family psychiatric and psychological factors associated with child physical health problems: results from the Boricua youth study. J Nerv Ment Dis. 2010;198:272-279.
73. Fagan MA. Exploring the relationship between maternal migraine and child functioning. Headache. 2003;43:1042-1048.

74. Guidetti V, Galli F, Fabrizi P, et al. Headache and psychiatric comorbidity: clinical aspects and outcome in an 8-year follow-up study. Cephalalgia. 1998;18:455-462.

75. Guidetti V, Pagliarini M, Cortesi F, et al. Mother and children with primary headache. A psychometric and psychological study. Minerva Med. 1987;78:1023-1026. Italian.

76. Benus RF, Bohus B, Koolhaas JM, van Oortmerssen GA. Heritable variation for aggression as a reflection of individual coping strategies. Experientia. 1991;47:1008-1019.

77. Marlowe N. Stressful events, appraisal, coping and recurrent headache. J Clin Psychol. 1998;54:247-256.

78. Cortelli P, Pierangeli G, Montagna P. Is migraine a disease? Neurol Sci. 2010;31 Suppl 1:S29-S31.

79. Balottin U, Chiappedi M, Rossi M, Termine C, Nappi G. Childhood and adolescent migraine: a neuropsychiatric disorder? Med Hypotheses. 2011;76:778-781

\section{Publish your work in this journal}

Neuropsychiatric Disease and Treatment is an international, peerreviewed journal of clinical therapeutics and pharmacology focusing on concise rapid reporting of clinical or pre-clinical studies on a range of neuropsychiatric and neurological disorders. This journal is indexed on PubMed Central, the 'PsycINFO' database and CAS.
The manuscript management system is completely online and includes a very quick and fair peer-review system, which is all easy to use. Visit http://www.dovepress.com/testimonials.php to read real quotes from published authors. 